\title{
BMJ Open Quality standards for safe medication in nursing homes: development through a multistep approach including a Delphi consensus study
}

\author{
Lea Domenica Brühwiler (D) , ${ }^{1}$ Andrea Niederhauser (D) , ${ }^{1}$ Simone Fischer, ${ }^{1}$ \\ David L B Schwappach (D) ${ }^{1,2}$
}

To cite: Brühwiler LD, Niederhauser A, Fischer S, et al. Quality standards for safe medication in nursing homes: development through a multistep approach including a Delphi consensus study. BMJ Open 2021;11:e054364. doi:10.1136/ bmjopen-2021-054364

- Prepublication history and additional supplemental material for this paper are available online. To view these files, please visit the journal online (http://dx.doi.org/10.1136/ bmjopen-2021-054364).

Received 10 June 2021 Accepted 24 September 2021

Check for updates

(c) Author(s) (or their employer(s)) 2021. Re-use permitted under CC BY-NC. No commercial re-use. See rights and permissions. Published by BMJ.

${ }^{1}$ Swiss Patient Safety Foundation, Zurich, Switzerland ${ }^{2}$ Institute of Social and Preventive Medicine (ISPM), University of Bern, Bern, Switzerland

\section{Correspondence to} Dr Lea Domenica Brühwiler; bruehwiler@patientensicherheit. ch

\section{ABSTRACT}

Objectives The aim of the study was to develop quality standards reflecting minimal requirements for safe medication processes in nursing homes.

Design In a first step, relevant key topics for safe medication processes were deducted from a systematic search for similar guidelines, prior work and discussions with experts. In a second step, the essential requirements for each key topic were specified and substantiated with a literature-based rationale. Subsequently, the requirements were evaluated with a piloted, two-round Delphi study.

Setting Nursing homes in Switzerland.

Participants Interprofessional panel of 25 experts from science and practice.

Primary and secondary outcome measures Each requirement was rated for its relevance for a safer and resident-oriented medication on a 9-point Likert-Scale based on the RAND/UCLA method. The requirements were considered relevant if, in the second round, the median relevance rating was $\geq 7$ and the proportion of ratings $\geq 7$ was $\geq 80 \%$.

Results Five key topics with a total of 87 requirements were elaborated and rated in the Delphi study. After the second round (response rate in both rounds 100\%), 85 requirements fulfilled the predefined criteria and were therefore included in the final set of quality standards. The five key topics are: (I) 'The medication is reviewed regularly and in defined situations', (II) 'The medication is reviewed in a structured manner', (III) 'The medication is monitored in a structured manner', (IV) 'All healthcare professionals are committed to an optimal interprofessional collaboration' and (V) 'Residents are actively involved in medication process'.

Conclusions We developed normative quality standards for a safer and resident-oriented medication in Swiss nursing homes. Altogether, 85 requirements define the medication processes and the behaviour of healthcare professionals. A rigorous implementation may support nursing homes in taking a step towards safer and resident-oriented medication.

\section{BACKGROUND}

Polypharmacy and potentially inappropriate prescribing (PIP) are increasingly prevalent in Swiss nursing homes as they
Strengths and limitations of this study

- This multistep and consensus-based study elaborated quality standards reflecting minimal requirements for the safe and resident-oriented medication in nursing homes.

- The Delphi study was designed according to established methodologies and used common indicators for consensus.

- The panel consisted of a large interprofessional group of experts from science and practice of which $100 \%$ responded in both rounds.

- As the Delphi panel was composed only of Swiss experts, generalisability to other countries and healthcare systems needs to be carefully checked.

are internationally. ${ }^{12}$ Polypharmacy may be associated with adverse drug events $(\mathrm{ADE})^{3}$ and with every additional drug prescribed the risk for problems related to medication increases. ${ }^{4}$ The occurrence of PIP poses an additional risk for $\mathrm{ADE}{ }^{56}$

The causes of ADE were evaluated in two large Canadian nursing homes. ${ }^{7}$ The study found that errors associated with preventable ADE mainly occurred at the medication prescribing and monitoring stages. Targeting these process stages in efforts to optimise the residents' medication may thus contribute to reducing $\mathrm{ADE}$. In fact, many intervention studies have successfully implemented new processes concerning the prescribing and monitoring stages or tools to nursing home staff to optimise medication and medicationrelated safety. The implementation of medication reviews, ${ }^{8}$ structured monitoring of the resident and their medication ${ }^{910}$ and the use of PIP-lists ${ }^{11}$ have for example shown benefits.

The implementation of such interventions in Switzerland is however scarce. With an online survey among directors of Swiss nursing homes in 2017, we assessed how 
widely safety-relevant medication processes are already implemented. ${ }^{12}{ }^{13}$ Of 420 participants, $35 \%$ stated that their institution does not perform regular medication reviews, $91 \%$ do not use a PIP-list and $93 \%$ have no standardised process to monitor side effects. We found that the implementation of these processes is heterogeneous and is associated with certain organisational characteristics. Nursing homes with low implementation of the processes in question often collaborated with several external family physicians and they were predominantly located in the German-speaking regions of Switzerland. A more homogeneous implementation of processes may partly be hindered by federalism, as a overview article on medication safety in Switzerland outlines. ${ }^{14}$ Regionally different law impairs nationally equal care practice.

The national programme 'progress! Medication safety in nursing homes' aims to promote a safer and residentoriented medication of Swiss nursing home residents. In the context of this programme, safe medication is defined as a drug therapy with well balanced risks and benefits. Specifically, the inappropriate use of polypharmacy should be addressed and PIP should be reduced. The residents' preferences should be respected by actively involving them in decision making. To achieve the programme goal, we sought to implement pre-existing practice guidelines describing processes for medication prescribing and monitoring. However, we did not find any guidelines that focused on the processes of interest, were precise enough, were applicable to Swiss nursing homes and addressed the whole interprofessional team.

Therefore, the goal of this study was to develop normative quality standards for safe medication in Swiss nursing homes. The quality standards should describe minimal requirements for prescribing, monitoring and reviewing medication in nursing homes. They should not provide guidance on drug choices in specific illness. In addition, they should not describe structural or outcome quality, nor be meant to measure quality, as quality indicators do. ${ }^{15}$ Lastly, the quality standards should address all healthcare professionals involved in the medication processes in nursing home residents, namely nurses, pharmacists and physicians. If rigorously implemented, the quality standards should contribute to a safer and resident-oriented medication in nursing homes.

\section{METHODS}

The quality standards were developed in three steps. First, we started with a systematic literature search in autumn 2018. Second, we developed key topics to be covered by the quality standards and drafted a first set of minimal requirements supported by evidence-based rationales. The 'key topics' together with their 'requirements' represent the 'quality standards'. Third, we used a Delphi consensus study to develop the final set of requirements in autumn 2019.

\section{Systematic literature search}

In a first step, we searched for practice guidelines for healthcare professionals describing good prescribing or medication review practice. We defined the following inclusion criteria: published no more than 10 years ago (2008-2018); published in English, German or French; report details of guideline development; and explicitly address the medication of nursing home residents or elderly patients. The search was conducted in three databases PubMed, Cinahl and Embase (search terms see online supplemental additional file 1) to identify scientifically developed and published guidelines.

The search was repeated in 16 guideline databases to find guidelines that were not published in scientific journals. The databases were known by the project team or found through unsystematic web search. They were mainly from Switzerland, Germany, UK, USA, Canada and Australia. The same or synonymous terms as for the scientific databases were used and translated if needed. In databases where no free text search was possible, document titles were screened. In this case, the documents were not preselected by search terms, therefore, it was not possible to count the total of screened documents from guideline databases.

\section{Development of key topics and requirements}

After the literature search, the project team consisting of a physician, a pharmacist, a nurse, a research associate, and a senior researcher developed the key topics to be covered. The key topics were deduced from three different sources. First, the two guidelines found in the systematic search (see results section) informed the range of topics to address. Second, knowledge gained from the first part of the national programme "progress! Medication safety in nursing homes', which included an online survey conducted among nursing home directors ${ }^{12} 131617$ and explorative interviews with 12 physicians provided information on the appropriateness of the topics. ${ }^{18}$ The findings from these studies pointed to a significant potential for improvement, most importantly in reviewing and monitoring the medication of nursing home residents in a more structured way. Furthermore, it became clear that the key topics also had to not only cover the collaboration between healthcare professionals, but also address the integration of residents. With these insights in mind, a first draft of five key topics was developed by the project team. Third, these drafts were discussed and counterchecked in informal and unstructured ways with experts of various professions to ensure their practical relevance.

For each of the key topics, several specific requirements were elaborated by the project team. The requirements describe more precisely what should be done by nursing home staff or what needs to be in place within the organisation to meet the key topic. To draft these requirements, the project team searched evidence pertinent to each key topic and of highest possible evidence level. In addition, different practice guidelines informed the definition of the requirements. The evidence for each key topic was 
summarised in a rationale to justify the suggested requirements. This first set of requirements was submitted for evaluation by the following Delphi panel.

\section{Delphi preparation}

Delphi panel members were purposefully selected to represent a wide range of expertise. Members of all healthcare professional groups addressed by the quality standards (physicians, pharmacists, nurses) were eligible as panellists if they had a comprehensive knowledge of geriatric medication. They had to be either researcher in the field of interest or practitioner working in nursing homes. The Delphi panel was required to represent all three main Swiss language regions (German, French, Italian), but the panellists had to be fluent in German or French to perform the Delphi. In addition, two experts in quality management and/or patient safety were enlisted for each language region. Retired professionals were not eligible. Members of the programme's advisory group and other experts known to the project team were contacted for participation. In addition, professional associations were asked to suggest representatives. Potential experts were contacted by email to obtain their consent to participate. With their consent, panellists agreed that their names and affiliations would be published with the final quality standards, but they remained anonymous during the Delphi process.

The Delphi process was piloted to test clarity and feasibility. Six professionals (one physician, two pharmacists, two nursing experts, one quality auditor) with practice experience and partly with research experience participated. Pilot participants received all documents as planned for the main Delphi rounds (see below) and were asked to complete the Delphi rating questionnaire sincerely. This allowed the project team to develop the evaluation method (ie, define a priori threshold rules, see below). Participants were informed, however, that their ratings would not be included in the final evaluation. Furthermore, participants were asked to provide feedback on the clarity and completeness of background information and instructions provided, and on any technical problems with the Delphi form, with rating or commenting. After the pilot, some minor adaptations were made to the documentation.

\section{Delphi rounds}

We performed a two-round Delphi study whose goal was to reach consensus about which requirements are relevant for a safer and resident-oriented medication of nursing home residents. The number of rounds was predefined, and no criteria were defined to stop the Delphi. The reporting is based on recommendations. ${ }^{19-21}$

For the first round, panellists received all necessary documentation by email. This included a description of the programme (background and aim), the purpose of quality standards and the methodology of their development, as well as a full version of the first set of quality standards including key topics, requirements (set 1) and rationales. In addition, the panellists received a modifiable excel sheet listing all the requirements to be rated and an instructional guide on how to complete the rating. They were asked to rate each requirement according to its relevance for a safer and residentoriented medication. To support this, a guiding question was provided: 'If this requirement is rigorously implemented in practice, how significant is its influence on a safer and resident-oriented medication?'. The instructional guide also provided definitions for 'relevance', for example, a requirement is highly relevant if its causal effect on the goal is large. Ratings were made on a 9-point Likert scale according to the RAND/UCLA Appropriateness Method, ${ }^{22} 9$ being highly relevant, 1 being not relevant at all. Panellists were informed that highly relevant requirements would be selected after the second round, without specifying what thresholds are applied. Panellists were asked to remain as consistent as possible in their ratings. Individual ratings were only visible to the project team, not to other panellists. In the first round, panellists had the possibility to add requirements (two empty lines per key topic) and to comment on the content, wording or on their own rating for each requirement. Abstentions should be avoided but they remained technically possible. The five key topics per se were not subject of the rating. In addition, panellists were explicitly asked not to consider feasibility of implementation, that is, not dismiss clinically relevant requirements due to feasibility reasons.

The exact dates for the two Delphi rounds with deadlines were communicated to panel members beforehand, so that they could reserve time slots accordingly. The first round started on 30 September 2019, the second round started on 28 October 2019. Both rounds lasted 14 days, with a reminder sent on day 11 to all panellists not having sent in their ratings.

After the first round, requirements of set 1 were adapted according to predefined adaptation rules to form set 2 . The rules concerned the level of relevance (LOR, ie, median of ratings) and the level of agreement (LOA, ie, proportion of all ratings being $\geq 7$ ). The following rules were defined: Requirements with an $\mathrm{LOR} \leq 3$ and with $\geq 80 \%$ of all ratings being $\leq 3$ were deleted for the second round. Ratings with a sufficiently high level of relevance (sLOR, defined as a median of ratings being $\geq 7$ ) and reaching a sufficiently high level of agreement (sLOA, defined as $\geq 80 \%$ of all ratings are $\geq 7$ ) are only modified if comments suggest important changes. All other requirements were modified according to comments. Meta-level comments about the key topics overall or about structure were ignored. Suggestions for new requirements were reviewed and added to set 2 if appropriate.

For the second rating round, participants received an updated set of documents, namely the full version of the quality standards with requirements (set 2, modifications highlighted) and an updated version of the instructional guide. The guide now contained detailed information on the predefined thresholds that are applied for the evaluation. In the excel rating sheet, modifications were not highlighted, but aggregated results from the first rating round (LOR and LOA for each requirement) were displayed. For newly added or substantially amended requirements, no results were provided. In the second 
round, no new requirement could be suggested. Panellists were again asked to avoid (technically possible) abstentions.

To evaluate the second round, thresholds were defined a priori guided by literature. ${ }^{19-22}$ The following criteria were defined: Requirements were included in the final set if they reach sLOR and sLOA. In addition, requirements were only included in the final set if at least $1 / 3$ of all panellists ( $=9$ members) gave a rating. Ratings from all panellists were assigned equal weight. No limitation for the number of requirements per quality standard was predefined.

\section{RESULTS}

\section{Literature search}

The literature search in scientific databases returned eight results for nursing home residents and 413 results for elderly patients (flow chart in online supplemental additional file 2). Of those 421 results, however, none of the papers met all inclusion criteria. Papers had to be excluded mainly because they reported observational or intervention studies or were focusing on a specific disease, drug or drug group. The search in guideline databases yielded one guideline for nursing home residents that met the inclusion criteria ${ }^{23}$ and two guidelines for older patients. ${ }^{24}{ }^{25}$ One of those guidelines was not suitable for our purposes because of its structure according to medical indications and was therefore excluded a posteriori. ${ }^{25}$

In the end, two guidelines served as basis for the development of our key topics. ${ }^{23}{ }^{24}$ The German College of General Practitioners and Family Physicians published a text-book style guideline on polypharmacy in 2014, providing recommendations to family physicians on how to manage polypharmacy at each of the different stages in the medication process. ${ }^{24}$ The guideline advises what steps to take and what to consider while prescribing, reviewing or monitoring medication. The National Institute for Health and Care Excellence published a guideline on 'managing medicines in care homes' in 2014, which targets all professionals involved. ${ }^{23}$ This guideline encompasses good practice recommendations on prescribing and reviewing medicines, but it also covers other subjects such as handling and administering medication to residents.

\section{Development of key topics and requirements}

Five key topics with a first set of 87 requirements were developed (summarised in table 1 and provided in detail in online supplemental additional file 3). Subtitles were

Table 1 Composition of different sets of requirements throughout the Delphi

\begin{tabular}{|c|c|c|c|c|c|c|c|}
\hline \multirow[b]{2}{*}{ Key topic } & \multicolumn{5}{|l|}{ Round 1} & \multicolumn{2}{|l|}{ Round 2} \\
\hline & $\begin{array}{l}\text { All rated } \\
\text { (set 1) }\end{array}$ & $\begin{array}{l}\text { unchanged } \\
\text { (reaching sLOR } \\
\text { and sLOA) }\end{array}$ & $\begin{array}{l}\text { changed } \\
\text { (reaching } \\
\text { sLOR and } \\
\text { sLOA) }\end{array}$ & $\begin{array}{l}\text { changed (not } \\
\text { reaching sLOR } \\
\text { and/or SLOA) }\end{array}$ & new & $\begin{array}{l}\text { All rated } \\
\text { (set 2) }\end{array}$ & $\begin{array}{l}\text { Accepted } \\
\text { (final set) }\end{array}$ \\
\hline $\begin{array}{l}\text { I: The medication is } \\
\text { reviewed regularly and in } \\
\text { defined situations }\end{array}$ & 20 & 11 & $3^{*}$ & $6 \dagger$ & 0 & 19 & 15 \\
\hline $\begin{array}{l}\text { III: The medication is } \\
\text { monitored in a structured } \\
\text { manner }\end{array}$ & 13 & 8 & $3 \ddagger$ & 2 & $2 \ddagger$ & 15 & 14 \\
\hline $\begin{array}{l}\text { V: Residents are actively } \\
\text { involved in medication } \\
\text { process }\end{array}$ & 6 & 5 & 1 & 0 & 0 & 6 & 6 \\
\hline Total & 87 & 63 & 13 & 11 & 5 & 91 & 85 \\
\hline
\end{tabular}

The five key topics with the number of their requirements are shown: Composition of requirements of set $1(n=87)$ with their amendments after round 1, composition of set $2(n=91)$ and the final set $(n=85)$

*One of those requirements was moved to the foreword, as it was a general remark, and therefore, was no longer part of the requirements.

†One of those requirements was not changed despite indication.

$\ddagger$ Two of those requirements reached SLOR and SLOA but were separated into four requirements (categorised as two changed and two new).

sLOA, sufficiently high level of agreement; sLOR, sufficiently high level of relevance. 
Table 2 Characteristics of the 25 Delphi members, with the field they represent (science (s) or practice (p))

\begin{tabular}{lllll}
\hline Language region & Physicians & Pharmacists & Nurses & Quality management \\
\hline German & $4(1 \mathrm{~s}, 3 \mathrm{p})$ & $2(2 \mathrm{~s})$ & $4(2 \mathrm{~s}, 2 \mathrm{p})$ & 1 \\
French & $1(1 \mathrm{~s})$ & $5(2 \mathrm{~s}, 3 \mathrm{p})$ & $4(2 \mathrm{~s}, 2 \mathrm{p})$ & 2 \\
Italian & $1(1 \mathrm{~s})$ & $1(1 \mathrm{p})$ & 0 & 0 \\
Total & $6(3 \mathrm{~s}, 3 \mathrm{p})$ & $8(4 \mathrm{~s}, 4 \mathrm{p})$ & $8(4 \mathrm{~s}, 4 \mathrm{p})$ & 3 \\
\hline
\end{tabular}

Panellists from quality management were not assigned to either science or practice.

not counted as requirement. This first set of quality standards was subsequently evaluated by the Delphi panel.

\section{Delphi study}

Twenty-five experts participated in the Delphi study. Their characteristics are shown in table 2. Response rate for both rounds was $100 \%$.

The results of the first round are summarised in table 1 and provided in detail in online supplemental additional file 3. After the first round, no requirement had an LOR of $\leq 3$ and a proportion of ratings $\leq 3$ being $\geq 80 \%$. Of 87 requirements, $76(87 \%)$ reached the sLOR and sLOA thresholds. However, 13 of those needed amendment due to important comments. 11 requirements did not reach sLOR and/or sLOA and were revised except in one case where comments did not suggest specific changes and the requirement was already short and clear. Five new requirements were added. The median number of ratings given per requirement was 25.

In the second round, 91 requirements were rated (results summarised in table 1 and in detail with ratings for each requirement in online supplemental additional file 4). Of those, 85 requirements met predefined sLOR and sLOA criteria, thus were considered relevant and were included in the final set of quality standards. This was the case for all requirements of key topics IV and V. Six requirements in key topics I-III had to be removed from the final set, since they reached the sLOR but not the sLOA, that is, reached no consensus. The requirements were not further adapted, except minor changes in language for better understanding. The final set of quality standards, composed of five key topics with the requirements, is shown in the online supplemental additional file 4 .

Consensus formed over the two rounds, as the median LOA was between $82 \%$ and $100 \%$ in first round and between $96 \%$ and $100 \%$ in second round. Median LOR for all key topics remained nine in both rounds.

\section{DISCUSSION}

In this study, we developed quality standards for a safer and resident-oriented medication in nursing homes. They were elaborated in an evidence-based and consensus-based process for Swiss nursing home practice. The final quality standards consist of five key topics with 85 requirements, representing minimal standards for the behaviour of healthcare professionals and institutions. The five key topics identified are: (I) 'The medication is reviewed regularly and in defined situations', (II) 'The medication is reviewed in a structured manner', (III) 'The medication is monitored in a structured manner', (IV) 'All healthcare professionals are committed to an optimal interprofessional collaboration' and $(\mathrm{V})$ 'Residents are actively involved in medication process'.

Overall, the requirements reached very high relevance ratings and high LOA among the experts. The LOA increased between the first and second round and only a few requirements had to be excluded from the final set. Lowest LOA was seen in key topic I and most of the eliminated requirements belonged to this topic. A reason for this may be that some of its requirements describe behaviours that have not yet been widely implemented in current practice, for example, reviewing the medication after readmission from hospital. The ratings possibly reflect the perception that high quality resident care is already provided even without such time-consuming practices. Even if this requirement received low approval by the panel, it reached the needed thresholds. This confirms findings from literature, that medication is substantially amended during hospitalisation, contains more suboptimal drugs and therefore may need special attention. ${ }^{2627}$ Four requirements of key topic I were finally rejected by the Delphi. One of these rejected requirements was the use of aggregated (rather than individual) data on medication for analyses, for example, to identify and target trends of suboptimal proton pump inhibitor use. The reluctance towards this approach is consistent with findings from a Swiss intervention trial published after the Delphi was conducted..$^{28}$ The intervention consisted of an analysis of population aggregated data followed by interprofessional quality circles where professionals agreed on deprescribing strategies for specific drug classes. The intervention showed an inconclusive effect on the individual medication overall, supporting expert ratings in our study. However, an effect of the intervention was seen in prescription rates of specific drug groups that were addressed in the quality circles, such as proton pump inhibitors. This indicates that drug class aggregated data may be useful for discussions around deprescribing in this drug class, but not for achieving broader, general deprescribing effects. 
Some of the requirements reaching sufficient but rather lower levels of agreement concerned the role of pharmacists. Evidence suggests that involving pharmacists in medication reviews can contribute to safe medication use. ${ }^{829}$ In Switzerland, however, pharmacists are not yet widely involved in medication reviews in nursing homes. ${ }^{12}{ }^{16}$ This is partly due to heterogeneous regulations concerning the (compulsory) collaboration between pharmacists and nursing homes, and the fact that in several regions, physicians can dispense medication to nursing home residents by themselves. ${ }^{12}$ The heterogeneity in current practice may have, therefore, influenced the ratings of Delphi panellists in regard to the pertinence of strengthening the pharmacists' role.

The quality standards strongly emphasise the collaboration between different healthcare professionals and emphasise that ensuring medication safety is an interprofessional task. Interprofessional collaboration has been found beneficial in reviewing and monitoring medication $^{8-10} 30$ and may be a facilitating factor in enhancing medication safety. ${ }^{31} 32$ Our quality standards contain general rules for good collaboration, and also describe processes that should be performed together and/or build on the competencies and experiences of different professionals. When performing a medication review, for example, the pharmacist starts with a pharmaceutical analysis of the medication. Nurses in turn add their specific observations from daily care, for example changes in resident's health status or potentially suboptimal therapies. In a last step, the physician summarises and completes all drug related problems identified and develops an action plan. Due to the great emphasis to interprofessional care, our quality standards, therefore, address all healthcare professionals. This differentiates the standards from other guidelines on similar topics which address, for example, only pharmacists ${ }^{33}$ or family physicians. $^{24}$

Another important aspect in our quality standards is that they highlight the importance of reviewing and optimising drug therapy for all residents, even for residents without any acute problems. Medication reviews are often initiated only if something changes in the health status or care of a resident. Residents in stable health do not see a physician regularly and often, their medication remains unchanged as long as there are no substantial problems with the therapy. This is a circumstance that may lead to long-term use of potentially inappropriate medications. ${ }^{1}$ Our quality standards, therefore, specifically define intervals in which medication should be reviewed.

With this study, we aimed to develop what would be considered a 'gold standard' for safe medication processes, solely driven by its clinical relevance and not by feasibility arguments. In a next step, these quality standards will have to be implemented in practice. It is clear that uptake by front-line healthcare professionals will require time and effort. A stepwise implementation of single key topics or even single requirements may be helpful. Implementation can be enforced by regulation or facilitated by certification incentives. Furthermore, remuneration of certain of the suggested processes, such as performing regular medication reviews, is essential. A lack of remuneration is considered to be an important reason why healthcare practitioners were so far reluctant to perform them. For implementation success, acceptance by the target group is a prerequisite. As we involved the affected professional groups and practitioners from the field, we expect that acceptance of the standards can be achieved. To assess adherence to the quality standards (ie, what should be done), valid and reliable process indicators (ie, what is being done) must first be operationalised. The quality standards are normative and are not specific enough to serve as process or outcome indicators. Outcome indicators (ie, what has been achieved) are already established in nursing homes. ${ }^{15}$ One of these outcome indicators is 'polypharmacy', that is, the proportion of residents taking nine or more drugs during the last 7 days.

There are some limitations regarding the content of the quality standards. They focus only on some aspects of patient care, namely medication review and monitoring. In comparison, other guidelines include a much broader range of additional processes such as prescribing, remote prescribing by telephone or storage of drugs. ${ }^{23}$ Our quality standards do not provide guidance on which medication to prescribe in specific cases, nor do they alert professionals of possibly harmful situations, as other guidelines do. ${ }^{24}$ Furthermore, they do not address diagnostics and routine and mandatory prescription validation when the pharmacist fills the prescription. Lastly, there are clinical situations in which it is not appropriate to follow our quality standards, for example, in end-of-life care.

The study must also be viewed in light of some methodological strengths and limitations. We performed a systematic literature search in 19 different databases, but very few relevant publications were found. Consulting additional guideline databases, for example from more different countries, could have been useful to detect other guidelines relevant to our work. The Delphi method is an established consensus finding method which goes beyond individual rating and in fact, consensus was built over the two rounds in our study. We designed the Delphi process according to established methodologies ${ }^{22}$ performed a common and feasible number of rounds ${ }^{19}$ and used established indicators for consensus (median score of ratings and percentage of agreement).$^{20}$ Also, the above-average number of panellists ${ }^{20}$ and their complete response rates in both rounds provided additional strength to our Delphi study. The selection of panel members may have been too convenient. However, as Switzerland is a small country, recruiting a large panel with experts independent of our national organisation and our large national programme was challenging. Many experts had been involved in the programme before and thus may have rated the requirements too positively. The recruitment of sufficient experts for the smaller Italian speaking part of Switzerland was not possible. But the still geographically quite dispersed 
panel is important to represent different national and professional cultures and may increase applicability of the quality standards to other countries.

We hypothesise that the quality standards are also pertinent to professionals in nursing homes in other countries, even if regulatory and organisational conditions differ. The standards only specify which tasks are relevant to perform (eg, that nurses should forward their observations), but not how to perform the task exactly (eg, how to forward it). They are, therefore, generalisable to different types of organising care (internationally) and their implementation can be adapted to local needs. However, the selection of requirements rated to be clinically relevant may of course have been influenced by practical problems and challenges encountered in daily practice by the experts. Countries with similar healthcare systems and conditions may especially benefit from the application of our quality standards. For example, nursing homes in Belgium and Germany are also confronted with a high number of external family physicians involved in resident care. $^{34}{ }^{35}$ It is therefore plausible that our requirements will be especially relevant for these countries.

\section{CONCLUSIONS}

The quality standards describe specific minimal standards for five key topics for the safer and resident-oriented medication in nursing homes. For Switzerland, they are the first standards developed with a multistep, evidencebased method, and they reached very high consensus in the Delphi study. The quality standards are normative and describe what would be considered a 'gold standard' for safe medication processes. They are not quality indicators and do not measure outcome or processes. We hypothesise that with their rigorous implementation, medication safety for nursing home residents may improve and interprofessional collaboration will be enhanced. In a next step, the quality standards have to be implemented in practice and tested for practicability and effectiveness for a safe and resident-oriented medication.

Acknowledgements The authors thank all panellists participating in the Delphi study and the professionals participating in the piloting. We acknowledge the contribution of Liat Fishman, Charlotte Vogel and Chantal Zimmermann, former employees at Patient Safety Switzerland, for support during preparation and conduct of the Delphi study.

Contributors Design (LDB and DLBS), conduct of literature research (LDB), composition of quality standards and first set of specification/requirement (all), acquisition of Delphi panel (LDB), conduct of Delphi (LDB, SF), data analysis (LDB, $A N)$, interpretation (all), drafting manuscript (LDB, AN), reviewing manuscript (SF, DLBS)

Funding This project was financially supported by the Federal Office of Public Health, Switzerland. Grant number 500.0005-7/1.

Competing interests None declared.

Patient consent for publication Not applicable.

Ethics approval The study did not require approval of an ethical committee according to Swiss federal Human Research Act.

Provenance and peer review Not commissioned; externally peer reviewed. Data availability statement Data are available on reasonable request.
Supplemental material This content has been supplied by the author(s). It has not been vetted by BMJ Publishing Group Limited (BMJ) and may not have been peer-reviewed. Any opinions or recommendations discussed are solely those of the author(s) and are not endorsed by BMJ. BMJ disclaims all liability and responsibility arising from any reliance placed on the content. Where the content includes any translated material, BMJ does not warrant the accuracy and reliability of the translations (including but not limited to local regulations, clinical guidelines, terminology, drug names and drug dosages), and is not responsible for any error and/or omissions arising from translation and adaptation or otherwise.

Open access This is an open access article distributed in accordance with the Creative Commons Attribution Non Commercial (CC BY-NC 4.0) license, which permits others to distribute, remix, adapt, build upon this work non-commercially, and license their derivative works on different terms, provided the original work is properly cited, appropriate credit is given, any changes made indicated, and the use is non-commercial. See: http://creativecommons.org/licenses/by-nc/4.0/.

\section{ORCID iDs}

Lea Domenica Brühwiler http://orcid.org/0000-0003-2703-3489

Andrea Niederhauser http://orcid.org/0000-0003-0107-5613

David L B Schwappach http://orcid.org/0000-0001-8668-3065

\section{REFERENCES}

1 Schneider R, Reinau D, Schur N, et al. Drug prescription patterns, polypharmacy and potentially inappropriate medication in Swiss nursing homes: a descriptive analysis based on claims data. Swiss Med Wkly 2019;149:w20126.

2 Abolhassani N, Vollenweider P, Waeber G, et al. Ten-Year trend in polypharmacy in the Lausanne population. $J$ Patient Saf 2021;17:e269-73.

3 Davies LE, Spiers G, Kingston A, et al. Adverse outcomes of polypharmacy in older people: systematic review of reviews. J Am Med Dir Assoc 2020;21:181-7.

4 Viktil KK, Blix HS, Moger TA, et al. Polypharmacy as commonly defined is an indicator of limited value in the assessment of drugrelated problems. Br J Clin Pharmacol 2007;63:187-95.

5 Dormann H, Sonst A, Müller F. Unerwünschte Arzneimittelereignisse bei älteren Notaufnahmepatienten: Bedeutung Der potenziell inadäquaten Medikation für ältere Menschen (PRISCUS). Dtsch Arztebl Int 2013:110:213-9.

6 Xing XX, Zhu C, Liang HY, et al. Associations between potentially inappropriate medications and adverse health outcomes in the elderly: a systematic review and meta-analysis. Ann Pharmacother 2019;53:1005-19.

7 Gurwitz JH, Field TS, Judge J, et al. The incidence of adverse drug events in two large academic long-term care facilities. Am J Med 2005;118:251-8.

8 Alldred DP, Kennedy M-C, Hughes C. Interventions to optimise prescribing for older people in care homes. Cochrane Database Syst Rev2016:1-68.

9 Thürmann PA, Jaehde U. Abschlussbericht zum Projekt ArzneiMitteltherapiesicherheit bei Patienten in Einrichtungen der Langzeitpflege (AMTS-AMPEL), 2016. Available: www.amts-ampel. de/publikationen

10 Jordan S, Gabe-Walters ME, Watkins A. Nurse-led medicines' monitoring for patients with dementia in care homes: A pragmatic cohort stepped wedge cluster randomised trial. PLoS One 2015;10:1-27.

11 Hill-Taylor B, Walsh KA, Stewart S, et al. Effectiveness of the STOPP/ START (screening tool of older persons' potentially inappropriate Prescriptions/Screening tool to alert doctors to the right treatment) criteria: systematic review and meta-analysis of randomized controlled studies. J Clin Pharm Ther 2016;41:158-69.

12 Niederhauser A, Brühwiler L, Fishman L, et al. Rapport de données: Résultats du sondage en ligne -Programme national progress ! La sécurité de la médication en EMS (also available in German and Italian), 2018. Available: www.securitedespatients.ch/ems

13 Niederhauser A, Brühwiler LD, Fishman L. Ausgewählte sicherheitsrelevante Medikationsprozesse in Schweizer Alters- und Pflegeheimen: status quo und Optimierungspotenziale. Z Evid Fortbild Qual Gesundhwes 2019;146:7-14.

14 Fishman L, Brühwiler L, Schwappach D. Medikationssicherheit: Wo steht die Schweiz? - Medication safety in Switzerland: Where are we today? Bundesgesundheitsblatt 2018;61:1152-8.

15 Zúñiga F, Blatter C, Wicki R. Nationale Qualitätsindikatoren in Schweizer Pflegeheimen. Fragebogenerhebung Zur Zuverlässigkeit 
Der Daten und Nützlichkeit AUS Sicht Der Anwender. Z Gerontol Geriatr 2019:52:730-6.

16 Brühwiler L, Niederhauser A, Fishman L. Services provided by pharmacists in Swiss nursing homes - progress! Medication safety in nursing homes. ESCP Symposium Belfast 2018 www. patientensicherheit.ch/pflegeheime

17 Stiftung Patientensicherheit Schweiz. Zusammenfassung des Schlussberichts zum Grundlagenprojekt (Dezember 2016-Dezember 2018) - Pilotprogramm progress ! Sichere Medikation in Pflegeheimen (also available in French and Italian), 2019. Available: www.patientensicherheit.ch/pflegeheime

18 Brühwiler L, Niederhauser A, Vogel C, et al. Zusammenfassung Ärzteinterviews - Anhang zum Schlussbericht zum Grundlagenprojekt progress! Sichere Medikation in Pflegeheimen (Dezember 2016-Dezember 2018) (also available in French and Italian), 2019. Available: www.patientensicherheit.ch/pflegeheime

19 Diamond IR, Grant RC, Feldman BM, et al. Defining consensus: a systematic review recommends methodologic criteria for reporting of Delphi studies. J Clin Epidemiol 2014;67:401-9.

20 Boulkedid R, Abdoul H, Loustau M, et al. Using and reporting the Delphi method for selecting healthcare quality indicators: a systematic review. PLoS One 2011;6:e20476.

21 Jünger S, Payne SA, Brine J, et al. Guidance on conducting and reporting Delphi studies (CREDES) in palliative care: recommendations based on a methodological systematic review. Palliat Med 2017;31:684-706.

22 Fitch K, Bernstein SJ, Aguilar MD, et al. The RAND/UCLA Appropriateness Method User's Manual. Santa Monica, 2001. Available: https://www.rand.org/pubs/monograph_reports/MR1269. html

23 National Institute for Health and Care Excellence (NICE). Managing medicines in care homes - Social care guideline, 2014. Available: https://www.nice.org.uk/guidance/sc1

24 Bergert FW, Braun M, Ehrenthal K, et al. Hausärztliche Leitlinie Multimedikation, 2014. Available: https://www.degam.de/degamleitlinien-379.html

25 Deutsche Gesellschaft für Allgemeinmedizin und Familienmedizin (DEGAM). Multimorbidität S3-Leitlinie. Berlin, 2017. Available:
https://www.awmf.org/uploads/tx_szleitlinien/053-047I_S3_ Multimorbiditaet 2018-01.pdf

26 Neeman M, Dobrinas M, Maurer S, et al. Transition of care: a set of pharmaceutical interventions improves hospital discharge prescriptions from an internal medicine ward. Eur J Intern Med 2017;38:30-7.

27 Reich O, Rosemann T, Rapold R, et al. Potentially inappropriate medication use in older patients in Swiss managed care plans: prevalence, determinants and association with hospitalization. PLOS One 2014;9:e105425.

28 Cateau D, Ballabeni P, Niquille A. Effects of an interprofessional quality Circle-Deprescribing module (QC-DeMo) in Swiss nursing homes: a randomised controlled trial. BMC Geriatr 2021;21:289.

29 Forsetlund L, Eike MC, Gjerberg E, et al. Effect of interventions to reduce potentially inappropriate use of drugs in nursing homes: a systematic review of randomised controlled trials. BMC Geriatr 2011;11:16.

30 Nazir A, Unroe K, Tegeler M, et al. Systematic review of interdisciplinary interventions in nursing homes. J Am Med Dir Assoc 2013;14:471-8.

31 Reeves S, Pelone F, Harrison R. Interprofessional collaboration to improve professional practice and healthcare outcomes (review). Cochrane Database Syst Rev 2017;22:1-48.

32 Al-Jumaili AA, Doucette WR. Comprehensive literature review of factors influencing medication safety in nursing homes: using a systems model. J Am Med Dir Assoc 2017;18:470-88.

33 Pharmaceutical Society of Australia. Guidelines for pharmacists providing residential medication management review (RMMR) and quality use of medicines (QUM) services, 2011. Available: www.psa. org.au

34 Strauven G, Anrys P, Vandael E, et al. Cluster-Controlled trial of an intervention to improve prescribing in nursing homes study. J Am Med Dir Assoc 2019;20:1404-11.

35 Mahlknecht A, Krisch L, Nestler N, et al. Impact of training and structured medication review on medication appropriateness and patient-related outcomes in nursing homes: results from the interventional study InTherAKT. BMC Geriatr 2019;19:257. 